Original Article

\title{
GCMS/MS ANALYSIS AND CARDIOPROTECTIVE POTENTIAL OF CUCUMIS CALLOSUS ON DOXORUBICIN INDUCED CARDIOTOXICITY IN RATS
}

\author{
R. VARADHARAJAN ${ }^{a, b *}$, D. RAJALINGAM ${ }^{a, b}$, S. PALANI ${ }^{c}$ \\ aDept of Pharmaceutical Chemistry, Kamalakshi Pandurangan College of Pharmacy, Tiruvannamalai, Tamil Nadu, India, besearch Centre, \\ Manonmanium Sundaranar University, Tirunelveli, Tamil Nadu, India, cDept of Biotechnology, Anna Bioresearch Foundation, Arunai \\ Engineering College, Tiruvannamalai, Tamil Nadu, India \\ Email: vrajanomnivas@yahoo.co.in \\ Received: 22 May 2016 Revised and Accepted: 22 Jul 2016
}

ABSTRACT

Objective: The present investigations were undertaken to identify phytochemicals by GC MS/MS, to evaluate the cardioprotective and antioxidant activity of the ethanolic extract of leaves of Cucumis Callosus against DOX-induced cardiotoxicity in rats.

Methods: GC MS/MS method was carried out for identification of phyto-compounds present in the Cucumis Callosus. The Cardioprotective effect of Cucumis Callosus (CC) was determined by using Doxorubicin (DOX) intoxication of rats as experimental models. The extent of heart damage and effect of the plant extract was assessed by various biochemical parameters like alanine aminotransferase (ALT), aspartate aminotransferase (AST), alkaline phosphatase (ALP), total cholesterol (TC) and triglycerides (TGs) in blood serum and concentration of malondialdehyde (MDA), reduced glutathione (GSH), superoxide dismutase (SOD), catalase (CAT), glutathione peroxidase (GPx), glutathione-s-transferase (GST) in heart tissue were determined.

Results: In the Cucumis Callosus extract 32 compounds were identified by GC-MS/MS. Doxorubicin is used to bring significant changes in biochemical parameters and antioxidants in the heart. The pretreatment with Cucumis Callosus at two doses (250 mg/kg and $500 \mathrm{mg} / \mathrm{kg}$ ) to DOX treated rats significantly prevented the altered enzymes SGPT, SGOT, CPK and LDH, lipid profile LDL, VLDL, TGs, HDL, TC and antioxidant SOD, GSH, CAT, GSH-Px and MDA to near normal level. Serum urea, uric acid, and ALP which are increased on DOX administration registered near normal values on pretreatment with Cucumis Callosus.

Conclusion: This study showed that the cardioprotective and antioxidant activity of Cucumis Callosus, therefore scientifically rampart the use of this plant in traditional medicine for treatment of heart diseases.

Keywords: Cardioprotection, Cucumis Callosus, Doxorubicin, Lipoprotein, Antioxidant

(C) 2016 The Authors. Published by Innovare Academic Sciences Pvt Ltd. This is an open access article under the CC BY license (http://creativecommons. org/licenses/by/4. 0/) DOI: http://dx.doi.org/10.22159/ijpps.2016.v8i9.13292

\section{INTRODUCTION}

Myocardial infarction (MI) is characterized by necrosis of a portion of the heart muscle. It is one of the most frequent causes of death in the developing country. Coronary atherosclerosis has been frequently an underlying factor in the pathogenesis of MI. The acute event is often provoked by rupture of an atherosclerotic plaque, leading to the formation of an occlusive thrombus and vasospasm, which hinder the delivery of oxygen to the myocardial tissue Supplied by that artery [1].

Doxorubicin (DOX) is an anthracycline antibiotic that is rooted as a chemotherapeutic agent. The administration of DOX is known to induce numerous cardiotoxic effects, including transient arrhythmias, nonspecific electrocardiographic abnormalities, pericarditis, and acute heart failure $[2,3]$. Increased level of low density lipoproteins (LDL) [4] and serum total cholesterol [5] and decreased levels of high density lipoprotein (HDL) [6] are associated with increased risk of MI. DOXinduced cardiotoxicity in rat was associated with increased lipid peroxide levels in the myocardium [7]. Oxidative stress refined by free radicals or reactive oxygen species (ROS), as evidenced by a marked increase in production of lipid peroxidative products and transient inhibition of endogenous antioxidant defense, such as superoxide dismutase (SOD), catalase (CAT) and reduced glutathione (GSH) has been shown to incline the myocardial damage during MI [8].

A number of herbs are conventionally used in different countries during drug or toxin induced hepatic, renal, and cardiac disorders [9]. Cucumis callosus (Rottle.) Cong. is commonly known as Bitter Cucumber belongs to the Cucurbitaceae family. It grows in desert regions. In India it mainly grows in dry districts. It is reported to be light, bitter, hot abortifacient, purgative, blood purifier and cathartic [10]. The fruit is useful in biliousness, jaundice, cerebral congestion, colic, constipation, dropsy, fever, worms and sciatica $[11,12]$. Root is given in cases of abdominal enlargement, cough, asthma, and inflammation of the breast, ulcers, urinary diseases and rheumatism [13]. Oil from seeds is used for poisonous bits, bowel complaints, epilepsy and also for blackening the hair [14]. In India, ripe fruit eaten raw and used in curries, green fruit used as a vegetable, dried fruit rind and seeds used in curries.

Previous phytochemical investigations on this plant resulted in the discovery of the presence of flavonoids, alkaloids, steroids terpenoids and derivatives [15], a previous study reported the presence of alkaloids, Wilfortrine and Wilforine have been reported to possess immunosuppresive effects and cardioprotective activity [16]. Wilfortrine can inhibit leukemia cell growth in mice $[17,18]$ and show anti-HIV activity [19].

Previous studies reported that the presence of alkaloids in the Cucumis callosus extract which have cardioprotective activity, however, no scientific claims are available on the cardioprotective activities of Cucumis callosus. Therefore, this study was designed to investigate the cardioprotective activity of Cucumis callosus extract against DOX-induced cardiotoxicity in rats.

\section{MATERIALS AND METHODS}

\section{Plant material}

Leaves of Cucumis callosus were collected, identified and authenticated by a Botanist, Dr. K. Shanthi, governtment arts college, Tiruvannamalai. Voucher specimen (KPCP-10/2016) was retained in the, PG Department of Pharmaceutical chemistry, Kamalakshi Pandurangan College of Pharmacy, Tiruvannamalai, Tamil Nadu, India.

\section{Chemicals and reagents}

Doxorubicin was purchased from Microlabs, Tamilnadu. India. ALT, AST, ALP, CPK kit were procured form span Diagnostics, Surat, India. 
All other chemicals and solvent were of analytical grade and commercially available.

\section{Acute toxicity studies}

Acute oral toxicity study was performed as per OECD-423 guidelines (acute toxic class method), Albino rats $(\mathrm{n}=6)$ of single sex were selected for the acute toxicity study. Which received a single oral dose of $2000 \mathrm{mg} / \mathrm{kg}$ body weight of ethanol extract of combretum albidum. The dose was administered to overnight fasted rats and food was withheld fora further3-hours after administration of the drug and observed for signs of toxicity for a period of $14 \mathrm{~d}$.

\section{Extraction}

Leaves $(1000 \mathrm{~g})$ of Cucumis callosus were cleaned with water and dried, then they were powdered using a mechanical grinder to obtain a coarse powder. The coarse powder (500 g) was passed through 40 mesh sieve and extracted with ethanol $(90 / 10 \mathrm{v} / \mathrm{v})$ in a Soxhlet apparatus at $25^{\circ} \mathrm{C}$. The extract was freeze-dried and stored in a vacuum desiccator and the yield was $7 \mathrm{~g}$.

\section{GC-MS/MS analyses of ethanol extract of Cucumis callosus for} the determination of chemical composition

\section{GC programme}

Column BR-5MS (5\% Diphenyl/95\% Dimethyl poly siloxane), 30m x $0.25 \mathrm{~mm}$ ID x $0.25 \mathrm{~mm}$ df

Equipment Scion 436-GC Bruker,Carrier gas $1 \mathrm{ml}$ per min, Split 10:1,Detector TQ Quadrupole Mass Spectrometer,Software MS Work Station 8,Sample injected $2 \mathrm{ml}$.

\section{Oven temperature programme}

$110{ }^{\circ} \mathrm{C}$ hold for $3.50 \mathrm{~min}, \mathrm{Up}$ to $200^{\circ} \mathrm{C}$ at the rate of $10^{\circ} \mathrm{C} / \mathrm{min}-\mathrm{No}$ hold,Up to $280{ }^{\circ} \mathrm{C}$ at the rate of $5{ }^{\circ} \mathrm{C} / \mathrm{min}-9$ min hold,Injector temperature $280^{\circ} \mathrm{C}$,Total $\mathrm{GC}$ running time: $37.50 \mathrm{~min}$,

\section{MS programme}

Library used NIST Version-11,Inlet line temperature $290{ }^{\circ} \mathrm{C}$, Source temperature $250^{\circ} \mathrm{C}$, Electron energy $70 \mathrm{eV}$, Mass scan (m/z) 50-500 amu,Solvent Delay 0-3.5 min,Total MS running time: $37.50 \mathrm{~min}$

The identification of the constituents of the ethanolic extract of Cucumis callosus was performed using a mass spectrometer (Agilent $6890 /$ Hewlett-Packard 5975) fitted with an electron impact (EI) ion source. The ethanolic extract $(2.0 \mu \mathrm{l})$ of Cucumis callosus was injected manually in the split mode with a Hamilton syringe to the GC-MS for total ion chromatographic analysis. For quantitative analysis, the selected ion monitoring (SIM) mode was employed.

\section{Experimental animals}

Studies were carried out using Wistar male albino rats (150-200 g), obtained from the Institute of Veterinary Preventive Medicine (IVPM), Ranipet, and Tamilnadu, India. The animals were housed in polyacrylic cages $(38 \mathrm{~cm}, 23 \mathrm{~cm}$, and $10 \mathrm{~cm})$ and maintained under standard laboratory conditions with dark/light cycle (12/12 h). The animals were fed with standard pellet diet (supplied by the poultry research station, Nandhanam, India) and fresh water ad libitum. All the animals were acclimatized to lab conditions for a week before commencement of the experiment. All animal studies were performed in accordance to guidelines of CPCSEA and Institutional Animal Ethical Committee (IAEC) of Kamalakshi Pandurangan college of Pharmacy, Tiruvannamalai (Tamilnadu). CPCSEA registration number was 745/03/ac/CPCSEA and all the procedures were followed as per rules and regulation.

\section{Induction of experimental myocardial infarction}

Doxorubicin was dissolved in sterile double distilled water and injected subcutaneously into rats

$(20 \mathrm{mg} / \mathrm{kg}$ ) in group II, IV and V respectively, after the last dose of the extract to induce Cardiotoxicity.

\section{Experimental procedure}

Group 1: (Normal). Saline ( $0.75 \mathrm{ml} / \mathrm{animal})$, orally for $14 \mathrm{~d}$.
Group 2: (Drug control). Saline (0.75 ml/animal)+DOX $20 \mathrm{mg} / \mathrm{kg}$, single intraperitoneal injection after 14 th day.

Group 3: (Extract control). Cucumis callosus (500 mg/kg), orally for $14 \mathrm{~d}$.

Group 4: Cucumis callosus (250 mg/kg), orally for $14 \mathrm{~d}+\mathrm{DOX}(20$ $\mathrm{mg} / \mathrm{kg}$ ) single intraperitoneal injection after 14 th day

Group 5: Cucumis callosus (500 mg/kg), orally for $14 \mathrm{~d}+\mathrm{DOX}(20$ $\mathrm{mg} / \mathrm{kg}$ ) single intraperitoneal injection after 14th day

\section{Induction of experimental myocardial infarction}

Doxorubicin was dissolved in sterile double distilled water and injected subcutaneously into rats $(20 \mathrm{mg} / \mathrm{kg})$ in group II, IV and V respectively, after the last dose of the extract to induce Cardiotoxicity.

\section{Isolation of working heart preparation}

The animals were anesthetized with chloroform after $72 \mathrm{~h}$ of DOX administration, and then heart was punctured with a sterile syringe and blood was stored with EDTA, which is an anticoagulant agent and was excised out. Cardiac muscle from the lower third of the ventricle was collected and stored in liquid nitrogen for antioxidant studies.

\section{Biochemical analysis}

Blood samples were collected into tubes pre-coated with EDTA by vein puncture at baseline and post intervention. Serum was separated by centrifuging for $10 \mathrm{~min} 3000 \times g$ at $4{ }^{\circ} \mathrm{C}$. The serum used for the assay of urea, and uric acid which were being estimated by the methods of Natelson et al. [20] and Caraway et al. [21] respectively. The activities of serum glutamate-pyruvate transaminase (SGPT) and serum glutamate oxaloacetate transaminase (SGOT) were determined spectrophotometrically by the method of Mohun and Cook [22]. The lactate dehydrogenase $(\mathrm{LDH})$, creatine phosphokinase (CPK) and alkaline phosphatase (ALP) were determined by the methods of King [23]. The levels of total cholesterol and triglycerides (TGs) were estimated by the methods of Zlatkis et al. [24], Foster and Dunn [25]. Serum high density lipoprotein (HDL) was determined according to the method of Wilson and Spiger [26]. Serum low density lipoproteins (LDL) and very low density lipoproteins (VLDL) were calculated as VLDL=triglycerides $/ 5$ and LDL $=$ total cholesterol - $(\mathrm{HDL}$ cholesterol+VLDL cholesterol) respectively.

\section{Antioxidant assay}

The heart was dissected, immediately washed in ice-cold saline and a homogenate was prepared in $0.1 \mathrm{Mol} \mathrm{L}^{-1}$ Tris-HCl buffer ( $\mathrm{pH} 7.4$ ). The homogenate was centrifuged and the supernatant was used for the assay of antioxidant parameters. MDA content assayed by adding tissue homogenate to TBA aqueous solution and incubated, and then the MDA content was measured according to the method of Zhang $e t$ al. [27]. Superoxide dismutase (SOD) activity assayed by adding NADH and incubated, and then SOD activity was measured according to the method of Rai et al. [28]. CAT activity was determined from the rate of decomposition of $\mathrm{H}_{2} \mathrm{O}_{2}$ according to Bergmeyer, Gowehn, and Grassel [29]. Glutathione peroxidase (GSH$\mathrm{Px}$ ) activity was determined by measuring the decrease in GSH content after incubating the sample in the presence of $\mathrm{H}_{2} \mathrm{O}_{2}$ and $\mathrm{NaN}_{3}$ according to Hafemann et al. [30]. GSH reductase activity was assayed according to Carlberg and Mannervik [31] and Mohandas et al. [32]. Bergmeyer et al. [29]. Glutathione peroxidase (GSH-Px) activity was determined by measuring the decrease in GSH content after incubating the sample in the presence of $\mathrm{H}_{2} \mathrm{O}_{2}$ and $\mathrm{NaN} 3$ according to Hafemann et al. [30]. GSH reductase activity was assayed according to Carlberg and Mannervik [31].

\section{Statistical analysis}

The obtained results were analyzed for statistical significance using one-way ANOVA followed by Dunnet test using graphpad prism software statistical software for comparison with control group and DOX-treated group. $\mathrm{P}<0.05$ was considered as significant. 


\section{RESULTS}

\section{Acute toxicity}

It was observed that the administration of single oral dose 2000 $\mathrm{mg} / \mathrm{kg} /$ body weight of ethanol extract of Cucumis callosus to a rat, didn't induce drug-related toxicity and mortality in the animals, and it was safe up to the dose of $2000 \mathrm{mg} / \mathrm{kg} /$ body weight.

\section{GC-MS/MS analysis}

The ethanolic extract of Cucumis callosus is a complex mixture of many constituents, and 32 compounds were identified in this plant by GC-MS/MS (fig. 1, table 1). Glycerin, Hexadecanoic acid, methyl ester, Palmitoleic acid, n-Hexadecanoic acid, 9,12-Octadecadienoic acid (Z,Z)-, Oleic Acid, cis-13-Octadecenoic acid, Octadecanoic acid, 3,4-Dihydroisoquinoline, 1-[3-methoxybenzyl]-6-methoxy-,4HDibenzo[de,g]quinoline, 5,6,6a,7-tetrahydro-10,11-dimethoxy-6methyl-, (R)-, 3,4-Dihydroisoquinoline, 1-[3-methoxybenzyl]-6methoxy-,2,3,9,10-Tetrahydro-1,8-dioxa-7,12-diazadicyclopenta (b,j)phenanthrene, Furo (3,4-e)-1,3-benzodioxol-8(6H)-one, 6(1,2,3,4-tetrahydro-6,7-dimethoxy-2-methyl-1-isoquinolinyl)-,(R$\left.\left(\mathrm{R}^{*}, \mathrm{~S}^{*}\right)\right)$-, Campesterol, and Stigmasterol were identified in the ethanol extract of Cucumis callosus by relating to the corresponding peak area through coupled GC-MS. Most of the phytochemical compounds possess medicinal properties (eg. Antioxidant, antimicrobial, antitumor, hepatoprotective, hypocholesterolemic, and anti-inflammatory properties, as identified by Dr. Duke's Phytochemical and Ethnobotanical Databases).

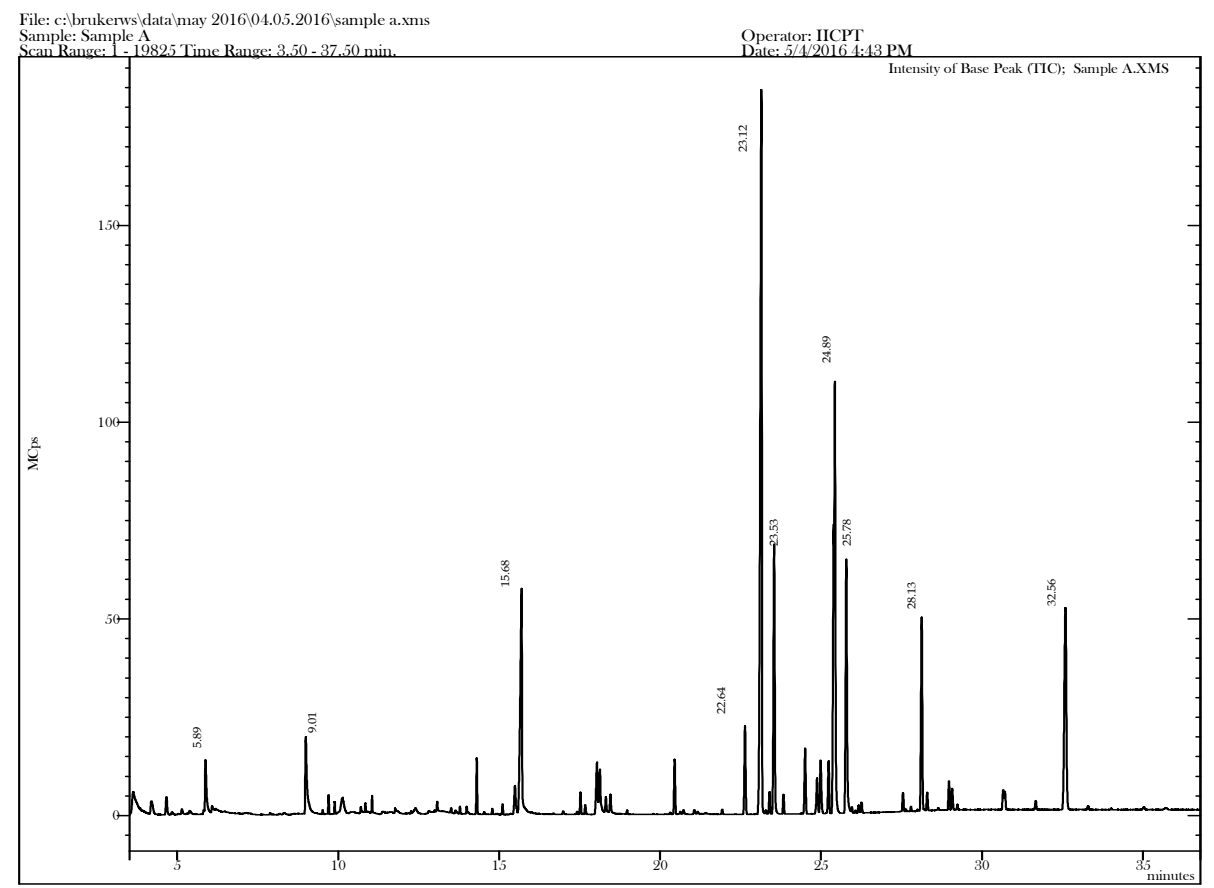

Fig. 1: The chromatogram showing n-Hexadecanoic acid (9.36), 4H-ibenzo[de,g]quinoline, 5,6,6a,7-tetrahydro-10,11-dimethoxy-6methyl-, (R)-(30.82), and Dodecane, 1-cyclopentyl-4-(3-cyclopentylpropyl)-(7.37) peaks detected by GC MS/MS

Table 1: Phytocomponents identified in Cucumis Callosus (GC-MS/MS study)

\begin{tabular}{|c|c|c|c|c|c|c|c|}
\hline S. No. & RT & Name of the compound & $\begin{array}{l}\text { Molecular } \\
\text { formulae }\end{array}$ & MW & $\begin{array}{l}\text { Peak area } \\
\%\end{array}$ & $\begin{array}{l}\text { Compound } \\
\text { nature }\end{array}$ & **Activity \\
\hline 1. & 3.68 & p-Cresol & C7H8O & 108 & 0.82 & $\begin{array}{l}\text { Phenolic } \\
\text { compound }\end{array}$ & $\begin{array}{l}\text { Antimicrobial, Anti-inflammatory } \\
\text { Antioxidant, Analgesic }\end{array}$ \\
\hline 2. & 4.19 & Phenylethyl Alcohol & $\mathrm{C} 8 \mathrm{H} 100$ & 122 & 0.25 & $\begin{array}{l}\text { Aromatic } \\
\text { compound }\end{array}$ & $\begin{array}{l}\text { Ingredient in flavors and } \\
\text { perfumery }\end{array}$ \\
\hline 3. & 4.66 & $\begin{array}{l}\text { 4H-Pyran-4-one, } 2,3- \\
\text { dihydro-3,5-dihydroxy-6- } \\
\text { methyl- }\end{array}$ & C6H804 & 144 & 0.27 & $\begin{array}{l}\text { Flavonoid } \\
\text { fraction }\end{array}$ & Antimicrobial, Anti-inflammatory \\
\hline 4. & 5.89 & 5-Hydroxymethylfurfural & C6H6O3 & 126 & 0.68 & $\begin{array}{l}\text { Aldehyde } \\
\text { compound }\end{array}$ & Antimicrobial, Anti-inflammatory \\
\hline 5. & 9.01 & Benzeneethanol, 4-hydroxy- & C8H10O2 & 138 & 0.18 & $\begin{array}{l}\text { Phenolic } \\
\text { compound }\end{array}$ & $\begin{array}{l}\text { Antimicrobial, Anti-inflammatory } \\
\text { Antioxidant, Analgesic }\end{array}$ \\
\hline 6. & 9.70 & $\begin{array}{l}\text { Benzene, 1-(1,5-dimethyl-4- } \\
\text { hexenyl)-4-methyl- }\end{array}$ & $\mathrm{C} 15 \mathrm{H} 22$ & 202 & 0.39 & $\begin{array}{l}\text { Aromatic } \\
\text { compound }\end{array}$ & No activity reported \\
\hline 7. & 10.15 & Lactose & $\mathrm{C} 12 \mathrm{H} 22011$ & 342 & 0.90 & Sugar moiety & Preservative \\
\hline 8. & 10.69 & Dodecanoic acid & $\mathrm{C} 12 \mathrm{H} 2402$ & 200 & 0.22 & Lauric acid & $\begin{array}{l}\text { Arachidonic acid inhibitor, Urine } \\
\text { acidifier }\end{array}$ \\
\hline 9. & 13.07 & Tetradecanoic acid & C14H2802 & 228 & 0.33 & Myristic acid & $\begin{array}{l}\text { Antioxidant, Cancer preventive, } \\
\text { Cosmetic, Hypercholesterolemic } \\
\text { Lubricant, Nematicide }\end{array}$ \\
\hline 10. & 13.99 & $\begin{array}{l}\text { 3,7,11,15-Tetramethyl-2- } \\
\text { hexadecen-1-ol }\end{array}$ & $\mathrm{C} 20 \mathrm{H} 400$ & 296 & 0.44 & Terpene alcohol & Antimicrobial, Anti-inflammatory \\
\hline 11. & 15.10 & $\begin{array}{l}\text { Hexadecanoic acid, methyl } \\
\text { ester }\end{array}$ & C17H3402 & 270 & 0.15 & $\begin{array}{l}\text { Palmitic acid } \\
\text { ester }\end{array}$ & $\begin{array}{l}\text { Antioxidant, Hypocholesterolemic } \\
\text { Nematicide, Pesticide, Lubricant }\end{array}$ \\
\hline
\end{tabular}


12. 15.49 Palmitoleic acid

13. 15.68 n-Hexadecanoic acid

14. $18.03 \quad 9,12$-Octadecadienoic acid $(\mathrm{Z}, \mathrm{Z})-$

15. $\quad 18.12$ Oleic Acid

\begin{tabular}{|c|c|c|}
\hline 16. & 18.32 & cis-13-Octadecenoic acid \\
\hline 17. & 18.46 & Octadecanoic acid \\
\hline 18. & 22.64 & $\begin{array}{l}\text { 3,4-Dihydroisoquinoline, } 1 \text {-[3- } \\
\text { methoxybenzyl]-6-methoxy- }\end{array}$ \\
\hline 19. & 23.12 & $\begin{array}{l}\text { 4H-Dibenzo[de,g]quinoline, } \\
\text { 5,6,6a,7-tetrahydro-10,11- } \\
\text { dimethoxy-6-methyl-, (R)- }\end{array}$ \\
\hline 20. & 23.53 & $\begin{array}{l}\text { 3,4-Dihydroisoquinoline, 1-[3- } \\
\text { methoxybenzyl]-6-methoxy- }\end{array}$ \\
\hline 21. & 24.49 & $(+)$-Roemerine \\
\hline 22. & 24.89 & $\begin{array}{l}\text { 2,3,9,10-Tetrahydro-1,8- } \\
\text { dioxa-7,12- } \\
\text { diazadicyclopenta(b,j)phena } \\
\text { nthrene }\end{array}$ \\
\hline
\end{tabular}

23. 25.24 Spiro[2,5-cyclohexadiene$1,7^{\prime}(1 ' \mathrm{H})$-cyclopent [ij]isoquinolin]-4-one, 2',3',8',8'a-tetrahydro-5',6'dimethoxy-1'-methyl-, (R)-

24. 25.42 Furo(3,4-e)-1,3-benzodioxol$8(6 \mathrm{H})$-one, 6- $(1,2,3,4$ tetrahydro-6,7-dimethoxy-2methyl-1-isoquinolinyl)-,(R-

$\left.\left(\mathrm{R}^{*}, \mathrm{~S}^{*}\right)\right)-$

$25.25 .78 \quad(-)-1,2,3,4-$

Tetrahydroisoquinolin-6-ol-1carboxylic acid, 7-methoxy-1methyl-, methyl ester

$26.28 .13 \quad 2-(\mathrm{p}-$ Methoxyphenyl)-8methyl-8H-thieno(2,3-

b)indole

27. 28.99 Condyfolan-16-carboxylic acid, 2,14,16,19-tetradehydro-, methyl ester, (14E)-

28. $30.69 \quad 1,3,5-C y c l o h e x a n e t r i o n e$, tris (dimethylaminomethylidene)-

29. 31.65 Stigmastan-3-ol, 5-chloro-, acetate, $(3 \beta, 5 \alpha)$ -

30. $32.56 \quad$ Dodecane, 1-cyclopentyl-4(3-cyclopentylpropyl)-

31. $\quad 35.01 \quad$ Campesterol

32. $\quad 35.70 \quad$ Stigmasterol
C16H30O2 $254 \quad 1.34$

C16H32O2 $256 \quad 9.36$

C18H32O2

280

1.89
$282 \quad 3.44$

С18H3402 $282 \quad 1.00$

C18H36O2 $284 \quad 1.02$

C18H19NO2 $281 \quad 3.17$

C19H21NO2 $295 \quad 30.82$

C18H19NO2 $281 \quad 5.83$

C18H17NO2 $279 \quad 1.54$

C16H12N2O2 $264 \quad 0.81$

C19H21NO3

311

2.35

C21H21NO6 $383 \quad 7.06$

Alkaloid

Unsaturated fatty

acid

Stearic acid

Alkaloid

Alkaloid

Alkaloid

Alkaloid

Polyaromatic compound

Alkaloid

Alkaloid

Alkaloid

Nitrogen

compound

C15H21N3O3 $291 \quad 2.45$

C31H53ClO2 $492 \quad 1.89$

C25H48

$348 \quad 7.37$

C28H480

400

2.54

C29H480
412
Nitrogen

compound

Steroid

Hydrocarbon

Steroid

Steroid
Antiandrogenic, Flavor, Hemolytic

9.5-Alpha reductase inhibitor

No activity reported

Antioxidant, Hypocholesterolemic Nematicide, Pesticide, Lubricant

Antiandrogenic, Flavor, Hemolytic

9.5-Alpha reductase inhibitor

Anti-inflammatory,

Hypocholesterolemic Cancer preventive, Hepatoprotective,

Nematicide Insectifuge,

Antihistaminic Antieczemic,

Antiacne, 5-Alpha reductase

inhibitor Antiandrogenic,

Antiarthritic, Anticoronary,

Insectifuge

Cancer preventive, Flavor,

Hypocholesterolemic, 5-Alpha

reductase inhibitor, Antiandrogenic,

Perfumery, Insectifuge, Anti-

inflammatory

Anemiagenic, Dermatitigenic

Choleretic

No activity reported

No activity reported

Antimicrobial, Anti-inflammatory

Antimicrobial, Anti-inflammatory

Antimicrobial, Anti-inflammatory

Cytotoxic

Antimicrobial, Anti-inflammatory

No activity reported

Antimicrobial

Anti-inflammatory

Antimicrobial

Anti-inflammatory

Antimicrobial

Anti-inflammatory

Antimicrobial

Anti-inflammatory

Antimicrobial
Antimicrobial

Antimicrobial, Anti-inflammatory Anticancer, Antiasthma, Hepatoprotective, Diuretic No activity reported

Antimicrobial, Anti-inflammatory Anticancer, Antiasthma, Hepatoprotective, Diuretic Antioxidant Anti-inflammatory Sedative Antihepatotoxic Canerpreventive Antiviral Ovulant Hypocholesterolemic Estrogenic Artemicide 


\section{Biochemical parameters}

The concentration of serum urea, uric acid, and alkaline phosphate was significantly increased in DOX-treated animals (group II) compared to normal animals (group I). Treatment with Cucumis callosus extract the levels of serum urea, uric acid, and alkaline phosphatase concentrations was decreased significantly (group IV and group V) compared with group II. (fig. 2).

The marker enzyme SGOT, SGPT, CPK, LDH were increased significantly in Group II compared with Group I (fig. 3 and 4). Cucumis callosus extract 250 and $500 \mathrm{mg} / \mathrm{kg}$ body weight (Group IV and V) treated animals marker enzymes levels were significantly reduced when compared with DOX-only treated group (group II).

The significant increase in levels of serum cholesterol, TGs, LDL and VLDL and decreased level in HDL were observed in DOX-treated rats when compared to the normal rats (group II). Pretreatment with Cucumis callosus ( 250 and $500 \mathrm{mg} \mathrm{kg}^{-1} \mathrm{~d}^{-1}$ for $14 \mathrm{~d}$ ) to DOX-treated rats significantly altered the level of serum cholesterol, TGs, LDL and VLDL (fig. 5 and 6) and increased the serum HDL concentration when compared to normal rats.

SOD, CAT, GSH-PX and GSH levels in DOX-induced rats (group II) were significantly decreased (fig. 7) when compared to normal rats (group $\mathrm{I}$ ). But the Cucumis callosus extract (250 and $500 \mathrm{mg} / \mathrm{kg} /$ day) counteracted dose-dependent manner and the detrimental effect of DOX by increasing the content of antioxidants. Administration of Cucumis callosus alone (group III) did not show significant changes in antioxidants when compared to normal rats (group I).

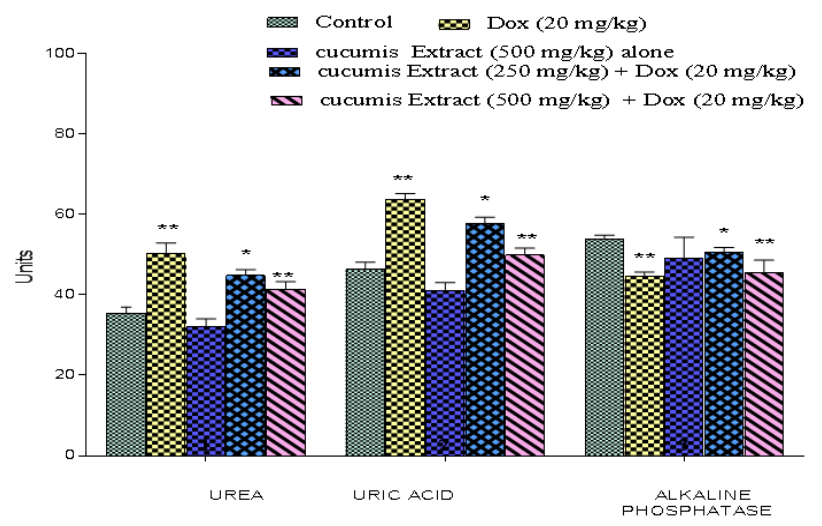

Fig. 2: Effect of ethanolic extract of cucumis callosus on urea $(\mathrm{mg} / \mathrm{l})$, uric acid (mg/l) and alkaline phosphatase $(\mathrm{mg} / \mathrm{l})$ in DOX intoxicated rats. Values are mean $\pm S D(n=6) * P<0.01, * * P<0.05$ respectively

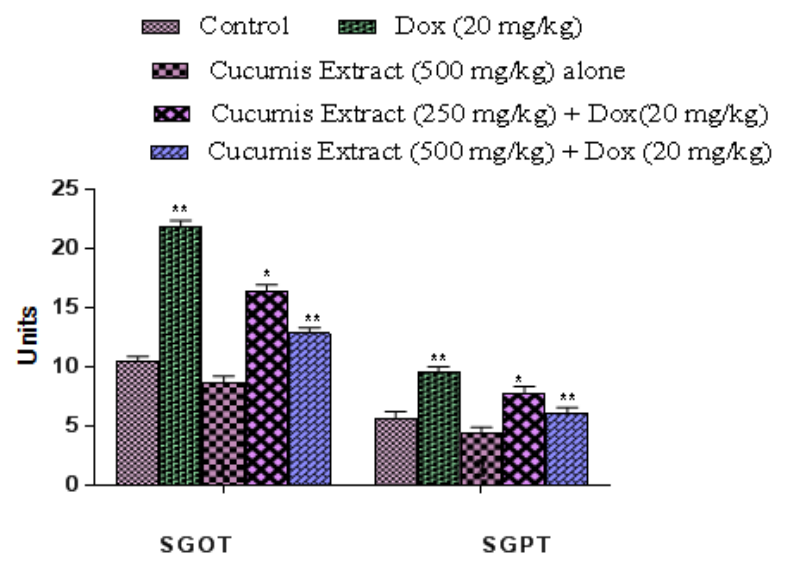

Fig. 3: Effect of ethanolic extract of cucumis callosus on SGOT (IU L ${ }^{-1}$ ) and SGPT (IU L $)^{-1}$ ) in DOX intoxicated rats. Values are mean $\pm S D(n=6) * P<0.01,{ }^{* *} \mathrm{P}<0.05$ respectively

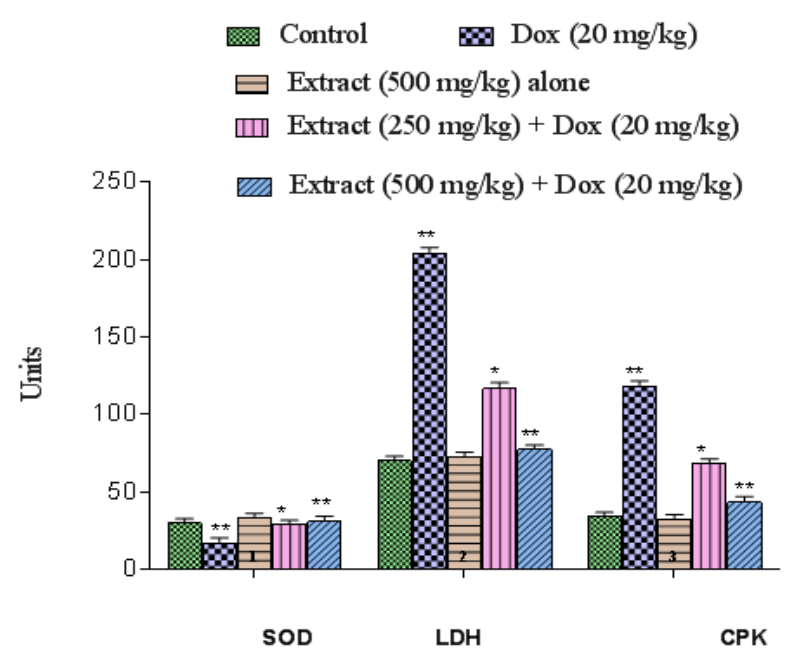

Fig. 4: Effect of ethanolic extract of cucumis callosus on SOD ( $U$ mg protein-1), LDH (IU L-1) and CPK (IU L ${ }^{-1}$ ) in DOX intoxicated rats. Values are mean \pm SD $(n=6){ }^{*} P<0.01$, ${ }^{* *} \mathrm{P}<0.05$ respectively

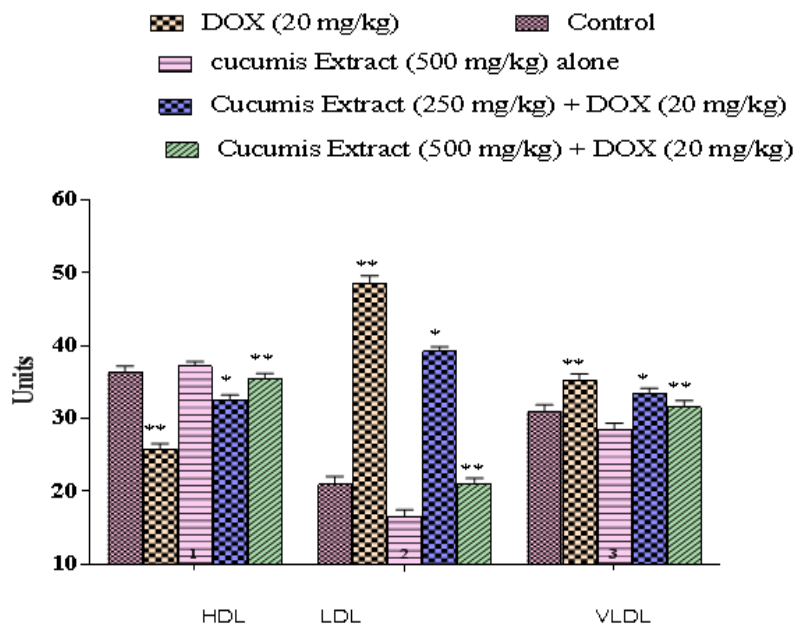

Fig. 5: Effect of ethanolic extract Cucumis on serum HDL $(\mathrm{mg} / \mathrm{l}), \mathrm{LDL}(\mathrm{mg} / \mathrm{l})$, and VLDL $(\mathrm{mg} / \mathrm{l})$ in DOX intoxicated rats. Values are mean $\pm S D(n=6) * P<0.01,{ }^{* *} \mathrm{P}<0.05$ respectively

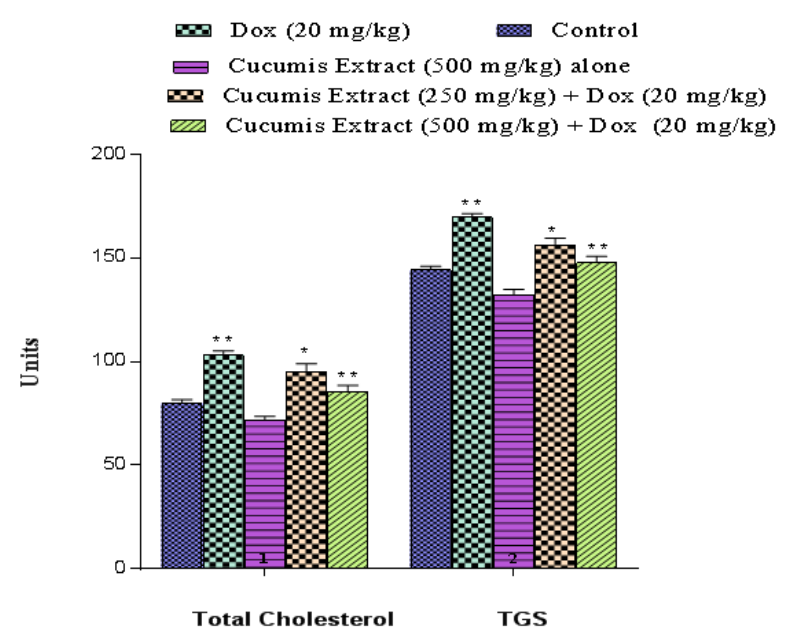

Fig. 6: Effect of ethanolic extract Cucumis on serum TGs (mg/l) and total cholesterol $(\mathrm{mg} / \mathrm{l})$ in DOX intoxicated rats. Values are mean $\pm S D(n=6) * P<0.01,{ }^{* *} \mathrm{P}<0.05$ respectively 


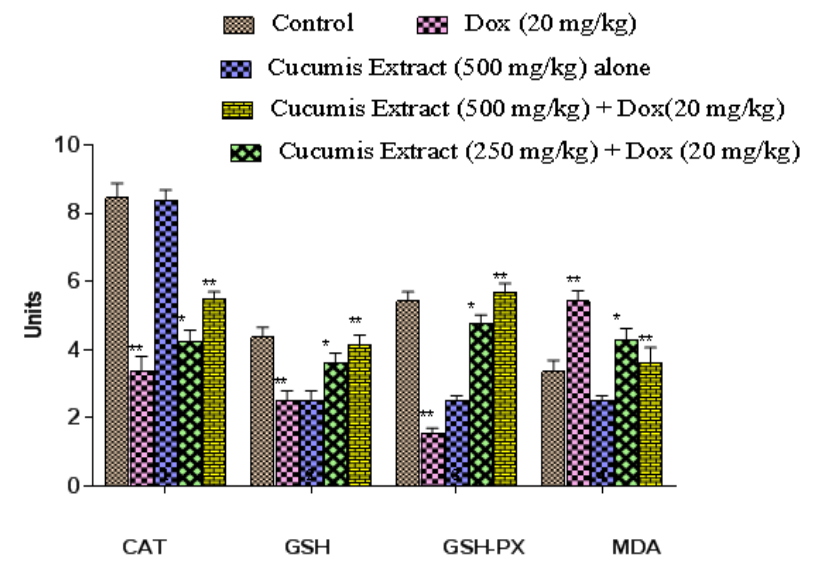

Fig. 7: Effect of ethanolic extract cucumis callosus on CAT $(\mu \mathrm{mol}$ of $\mathrm{H}_{202}$ consumed $\mathrm{min}^{-1} \mathrm{mg}$ protein $\left.^{-1}\right)$, GSH (mM gram tissue ${ }^{-1}$ ), GSH-Px ( $\mu \mathrm{g}$ of GSH oxidized min $^{-1} \mathrm{mg}^{-1}$ protein ${ }^{-1}$ ), and MDA (nmol $\left.\mathrm{g} \mathrm{tissue}^{-1}\right)$ in DOX intoxicated rats. Values are mean $\pm \operatorname{SD}(n=6)$ ${ }^{*} \mathrm{P}<0.01,{ }^{* *} \mathrm{P}<0.05$ respectively

\section{DISCUSSION}

This study entails the cardioprotective activity of ethanolic extract of Cucumis callosus against DOX-induced cardiotoxicity. The cardioprotective activity was proved by determining the level of serum marker enzymes (SGPT, SGOT, CPK and LDH) which are well known markers of myocardial infarction, When myocardial cells are damaged or destroyed due to deficient oxygen supply or glucose, the cardiac membrane becomes permeable or may rupture which results in leakage of enzymes.

These enzymes enter into the blood stream,thus increasing their concentration in the serum, it was showed, that oxygen-free radicals generated during Doxorubicin redox cycling are responsible for the damage that doxorubicin causes to the heart [33]. The level of these enzymes was decreased in the Cucumis callosus extract treated rats.

The cardioprotective activity of the Cucumis callosus was also proved by increased antioxidant enzyme activity and decreased lipid peroxidation. The existing experimental evidence suggests that doxorubicin oxidative stress is due to the generation of free radicals in the heart tissue [34]. The generated reactive oxygen species such as superoxide radicals and hydroxyl radicals are potential to cause damage to various intracellular components. Heart tissue is particularly susceptible to free-radical injury because it contains low levels of free-radical detoxifying enzymes/molecules like SOD, GSH and CAT. Further, doxorubicin also has high affinity for the phospholipid component of the mitochondrial membrane in the cardiac myocyte, leading to accumulation of doxorubicin in the heart tissue [35].

In our study the SOD activity was significantly decreased in DOX-treated animals and increase in the SOD activity was observed in Cucumis callosus pretreated animals in a dose-dependent manner. However, it has been reported that a rise in SOD activity, without a concomitant rise in the activity of catalase/GSH, might be detrimental [36] because the SOD activity increases the generation of hydrogen peroxide which is cytotoxic and needs to be scavenged by catalase/GSH. Thus a simultaneous increase in catalase/GSH activity is essential for an overall beneficial effect of an increase in SOD activity [37]. The oxidative stress and tissue injury caused by DOX was inhibited by the increased activity of GSH, SOD and catalase, following treatment of Cucumis callosus. The increase in catalase activity in DOX-treated animals supports the above hypothesis that this increase is possibly required to overcome excessive oxidative stress [38].

The increase in the level of plasma triglycerides, total cholesterol and low-density lipoproteins in the doxorubicin-treated group indicates doxorubicin may be interfering with metabolism or biosynthesis of lipids. Pretreatment with Cucumis callosus showed a reduction in blood lipid profile levels with a concomitantly increase in HDL cholesterol was observed. Decrease in the blood lipid profiles and increase in HDL cholesterol in Cucumis callosus treated group may be due to the presence of the synergetic effect of chemical compounds present in the extract.

Lipid-lowering effect of Cucumis callosus extract is due to inhibition of hepatic cholesterol biosynthesis, increased fecal bile acid secretion and stimulation of receptor-mediated catabolism of LDL cholesterol and increase in the uptake of LDL from the blood by liver [39].

Heart tissue injury induced by doxorubicin in rats was indicated by elevated levels of the marker enzymes such as serum LDH and CPK [40]. The increase of the LDH level in serum and extracellular fluid suggests an increased leakage of this enzyme from mitochondria as a result of toxicity induced by treatment with doxorubicin. This index has been recently used in other studies to test for cardiotoxicity [41].

Cucumis callosus was found to inhibit the doxorubicin-induced CPK and LDH release in the serum of rats. It is widely reported that doxorubicin-induced free-radical generation triggers membrane peroxidation and disruption of cardiac myocytes, which can lead to increased release of CPK in the serum. Cucumis callosus pretreatment led to inhibition of CPK and LDH release which resulted in either complete reversal or considerable recovery of the serum enzyme activities.

The Cardioprotective activity of Cucumis callosus was further supported by increased myocardial antioxidant enzyme activity and decreased the extent of lipid peroxidation. Lipid peroxidation is known to cause cellular damage and is primarily responsible for reactive oxygen species induced organ damage. Increased level of MDA and decreased levels of GSH, SOD and CAT were observed in heart tissue in doxorubicin-treated animals. Pretreatment with Cucumis callosus efficiently counteracted the doxorubicin-induced cardiac tissue damage by a significant decrease in MDA and the increase in GSH, SOD and CAT levels. The observed increase in CAT activity in doxorubicin-treated animals supports the above hypothesis that this increase is possibly required to overcome excessive oxidative stress [42].

\section{CONCLUSION}

In conclusion, the present results suggest that Cucumis callosus prevented the doxorubicin-induced myocardial toxicity by boosting the endogenous antioxidant activity. The cardioprotective property of Cucumis callosus could be due to lipid-lowering and antioxidant properties. Further studies are needed in isolation and characterization of chemical compounds present in the Cucumis callosus extract for the treatment of myocardial infarction.

\section{CONFLICT OF INTERESTS}

Declared none

\section{REFERENCES}

1. Alan R, Gaby MD. Nutritional treatments for acute myocardial infarction. J Alternative Complementary Med 2010;2:113-22.

2. Billingham ME, JW Mason, MR Bristow, JR Daniels. Anthracycline cardiomyopathy monitored by morphologic changes. Cancer Treat Rep 1978:62:865-72.

3. Bristow MR, PD Thompson, RP Martin, JW Mason, ME Billingham, DC Harrison. Early anthracycline cardiotoxicity. Am J Med 1978;65:823-32.

4. Brown MS, JL Goldstein. A receptor-mediated pathway for cholesterol homeostasis. Science 1986;232:34-47.

5. Grundy SM. Cholesterol and heart disease: a new era. JAMA 1986;256:2849-58.

6. Castelli WP, RJ Garrison, PWF Wilson, RD Abott, S Kalousidan, WB Kannel. The incidence of coronary heart disease and lipoprotein cholesterol levels. The framingham study. JAMA 1986;256:2835-8.

7. Myers CE, WP McGuire, RH Liss, I Ifrim, K Grotzinger, RC Young. Adriamycin: the role of lipid peroxidation in cardiac toxicity and tumor response. Science 1977;19:165-7.

8. Zhou R, Q Xu, P Zheng, L Yan, J Zheng, G Dai. Cardioprotective effect of fluvastatin on isoproterenol-induced myocardial infarction in rat. Eur J Pharmacol 2008;586:244-50.

9. El-Beshbishy HA. Hepatoprotective effect of green tea [Camellia sinensis] extract against tamoxifen-induced liver injury in rats. J Steroid Biochem Mol Biol 2005;38:300-6. 
10. Seliya AR, Patel NK. Ethnomedicinal uses of climbers from saraswati river region of patan district, North gujarat. Ethnobotanical Leaflets 2009;13:865-72.

11. ERHSS Ediriweera, WD Ratnasooriya. Ayu, newsletters Ayurved University, Sri Lanka; 2009;30:373-91.

12. Goyal M, Sharma SK. Traditional wisdom and value addition prospects of arid foods of the desert region of North West. India J Traditional Knowledge 2009;8:581-85.

13. Kirtikar KR, Basu BD. Indian Medicinal Plants. Vol. II. 4th ed. International Book Distributors, Dehradun; 1975. p. 1325.

14. Singh MP, H Panda. Medicinal Herbs With Their Formulation. S Daya. Publishing Hous; 2005. p. 311-2.

15. Payal Singh Soam, Tribhuwan Singh, Rekha Vijayvergia, C Jayabaskaran. Liquid chromatography-mass spectrometry based profile of bioactive compounds of Cucumis callosus. Eur J Exp Biol 2013;3:316-26.

16. Panda S, Kar A, Sharma P, Sharma A. Cardioprotective potential of $\mathrm{N}, \alpha$-L-rhamnopyranosyl vincosamide, an indole alkaloid, isolated from the leaves of Moringa oleifera in isoproterenol induced cardiotoxic rats: in vivo and in vitro studies. Bioorg Med Chem Lett 2013;23:959-62.

17. Deng FX, Cao JH, Xia ZL, Lin S, Wang XY. The structure of triptodihydroxy acid methyl ester and Wilfortriene. Acta Bot Sin 1987;29:73-6.

18. Zheng $\mathrm{YL}, \mathrm{Xu} \mathrm{Y,} \mathrm{Lin} \mathrm{JF.} \mathrm{Immunosuppressive} \mathrm{effects} \mathrm{of}$ wilfortrine and Euonine. Yaoxue Xuebao 1989;24:568-72.

19. Duan HQ, Takaishi Y, Imakura Y, Jia YF, Li D, Cosentino LM, et al. Sesquiterpene alkaloids from tripterygium hypoglaucum and tripterygium wilfordii: a new class of potent anti-HIV agents. J Nat Prod 2000;63:357-61.

20. Natelson S, ML Scott, C Beffna. A rapid method for the estimation of urea in biological fluids by means of the reaction between diacetyl and urea. Am J Clin Pathol 1951;21:275-81.

21. Seligson D. ed. Standard methods of clinical chemistry. Vol. 4. New York, NY: Academic Press; 1963. p. 239-47.

22. Mohun A, IJ Cook. Simple methods for measuring serum level of glutamic oxaloacetic and glutamic pyruvic transaminases in routine laboratories. J Clin Pathol 1957;10:394-9.

23. King J. Practical Clinical Enzymology. Dvan. Nostrand Co, London; 1965. p. 22, 83-93.

24. Zlatkis A, B Zak, GJ Boyle. A new method for the direct determination of serum cholesterol. J Clin Med 1953;41:486-92.

25. Foster LV, RT Dunn. Stable reagents for determination of serum triglycerides by a colorimetric Hatzsch condensation method. Clin Chem 1973;19:338-40.

26. Wilson DE, MJ Spiger. A dual precipitation method for quantitative plasma lipoprotein measurement without ultracentrifugation. J Lab Clin Med 1973;82:473-5.

27. Zhang XZ. Crop physiology research methods. China Agricultural Press: Beijing; 1992. p. 131-207.
28. Rai S, A Wahile, K Mukherjee, BP Saha, PK Mukherjee. Antioxidant activity of Nelumbo nucifera (sacred lotus) seeds. J Ethnopharmacol 2006;104:322-8.

29. Bergmeyer HU, K Gowehn, H Grassel. Enzymes as biochemical reagents. Weinheim: Verlag Chemie; 1974.

30. Hafemann DG, RA Sunde, WG Houestra. Effect of dietary selenium on erythrocyte and liver glutathione peroxidase in the rat. J Nutr 1974;104:580-4.

31. Carlberg I, B Mannervik. Glutathione reductase levels in rat brain. J Biol Chem 1975;250:5475-9.

32. Mohandas J, JJ Marshall, GG Duggin, JS Horvath, D Tiller. Differential distribution of glutathione and glutathione-related enzymes in rabbit kidney: possible interactions in analgesic neuropathy. Cancer Res 1984;44:5086-91.

33. Singal PK, N Iliskovic. Doxorubicin-induced cardiomyopathy. N Engl J Med 1998;339:900-5.

34. Hardina R, Gersl V, Klimtova I, Simunek T, Machacko va J, Adamcova M. Anthracycline-induced cardiotoxicity. Acta Med 2000;43:75.

35. Takacs IE, Matkovics B, Varga SI, Homolay P, Feer G, Seres T. Study of the myocardial antioxidant defense in various species. Pharm Res 1992;25:177.

36. Herman D. The aging process major risk factor for disease and death. Proc Natl Acad Sci 1991;88:5360-3.

37. Mukherjee S, SK Banerjee, M Maulik, AK Dinda, KK Talwar. Protection against acute doxorubicin-induced cardiotoxicity by garlic: role of endogenous antioxidants and inhibition of TNF- $\alpha$ expression. Biomed Central Pharmcol 2003;3:16-9.

38. Li T, Singhal PK. Doxorubicin-induced early changes in myocardial antioxidant enzymes and their modulation by probucol. Circulation 2015;102;2000.

39. Khanna AK, Ramesh C, Kapoor NK, Terminalia arjuna. An ayurvedic cardiotonic regulates lipid metabolism in hyperlipidemic rats. Phytother Res 1996;10:663.

40. Ahmed KK, Rana AC, Dixit VK. Effect of calotropis procera latex on isoproterenol induced myocardial infarction in albino rats. Phytomedicine 2004;11:327.

41. Smith MT, Bellomo G. Relationship between the mitochondrial transmembrane potential, ATP concentration, and cytotoxicity in isolated rat hepatocytes. Arch Biochem Biophys 1990;282:358.

42. Li T, PK Singhal. Doxorubicin-induced early changes in myocardial antioxidant enzymes and their modulation by probucol. Circulation 2000;102:2105-10.

\section{How to cite this article}

- $\quad$ R Varadharajan, D Rajalingam, S Palani. GCMS/MS analysis and cardioprotective potential of Cucumis callosus on doxorubicininduced cardiotoxicity in rats. Int J Pharm Pharm Sci 2016;8(9):239-245. 